\title{
Capsule Commentary on Vyas et al., Diet Drink Consumption and the Risk of Cardiovascular Events: A Report from the Women's Health Initiative
}

\author{
Cynthia Kay, MD MS
}

Clement J. Zablocki VAMC and Medical College of Wisconsin, Milwaukee, WI, USA.

J Gen Intern Med 30(4):493

DOI: $10.1007 / \mathrm{s} 11606-014-3109-1$

(c) Society of General Internal Medicine 2015

$\mathrm{T}$ his study by Vyas et al. is a retrospective report on data from the Women's Health Initiative assessing the relationship between the amount of diet soda consumed and incidence of cardiovascular disease (CVD). ${ }^{1}$ Nearly 60,000 postmenopausal women without known CVD were evaluated and followed for 6-10 years. Diet soda intake was categorized into four groups: 0-3 drinks per month, 1-4 drinks per week, 5-7 drinks per week, and 2 or more drinks per day.

After adjusting for a multitude of factors, including CVD risk and demographic characteristics, women who consumed $\geq 2$ drinks/day had a higher risk of CVD events and mortality compared to women who drank $0-3$ drinks/month. The authors also found an interesting interaction between BMI and diet drink intake, which could be further explored.

All observational epidemiological studies are prone to a number of important confounding variables that could produce biased results. In this study, there were differences between participants who were included in the study and those who were excluded, and the study's main focus relied on participants' responses to questionnaires. In addition, dietary data was obtained at baseline and three years after enrollment, and it is reasonable to assume that dietary behavior, including the number of diet drinks consumed, would vary over the years.
While diet soda is often considered a better alternative to regular soda, past studies have suggested that its consumption is tied to increased obesity, ${ }^{2}$ metabolic syndrome, ${ }^{2}$ and diabetes. ${ }^{3}$ This study offers further support that diet soda should not be considered a healthier substitute. However, the number of potential confounders in the relationship between diet soda and CVD is considerable. At most, such data should be cautiously interpreted to mean that there "might" be an association between the two. Medical history is rife with examples of putative relationships based on epidemiologic data, such as the benefit of estrogen for postmenopausal women or the importance of magnesium for heart attack survival, both of which proved to be unsubstantiated when studied more rigorously. Further research regarding the possible association between diet soda and CVD certainly remains an area of interest.

Corresponding Author: Cynthia Kay, MD MS; Clement J. Zablocki VAMC and Medical College of Wisconsin, 8701 Watertown Plank Road, Milwaukee, WI 53226, USA (e-mail: ckay@mcw.edu).

\section{REFERENCES}

1. Vyas A, Rubenstein L, Robinson J, Seguin RA, Vitolins MZ, et al. Diet drink consumption and the risk of cardiovascular events: a report from the women's health initiative. JGIM. 2014. doi:10.1007/s11606-014-3098-0.

2. Malik VS, Popkin BM, Bray GA, Després JP, Willett WC, Hu FB. Sugarsweetened beverages and risk of metabolic syndrome and type 2 diabetes. Diabetes Care. 2010;33(11):2477-2483.

3. De Koning L, Malik VS, Rimm EB, Willett WC, Hu FB. Sugar-sweetened and artificially sweetened beverage consumption and risk of type 2 diabetes in men. Am J Clin Nutr. 2011;93(6):1321-1327.

Published online January 8, 2015 